\title{
Bound to Succeed: Transcription Factor Binding-site Prediction and Its Contribution to Understanding Virulence and Environmental Adaptation in Bacterial Plant Pathogens
}

\author{
Surya Saha and Magdalen Lindeberg \\ Department of Plant Pathology and Plant-Microbe Biology, Cornell University, Ithaca, NY 14853, U.S.A.
}

Submitted 1 April 2012. Accepted 16 June 2013.

\begin{abstract}
Bacterial plant pathogens rely on a battalion of transcription factors to fine-tune their response to changing environmental conditions and to marshal the genetic resources required for successful pathogenesis. Prediction of transcription factor binding sites (TFBS) represents an important tool for elucidating regulatory networks and has been conducted in multiple genera of plant-pathogenic bacteria for the purpose of better understanding mechanisms of survival and pathogenesis. The major categories of TFBS that have been characterized are reviewed here, with emphasis on in silico methods used for site identification and challenges therein, their applicability to different types of sequence datasets, and insights into mechanisms of virulence and survival that have been gained through binding-site mapping. An improved strategy for establishing Evalue cutoffs when using existing models to screen uncharacterized genomes is also discussed.
\end{abstract}

Bacterial plant pathogens move between diverse environmental niches during the course of the disease cycle. For free-living bacteria, these can include soil, epiphytic surfaces, and different tissues within the plant host, while many fastidious bacteria, although more limited in their niche flexibility, nonetheless move between plant hosts and insect vectors. Survival and successful pathogenesis require the pathogen to sense and effectively respond to the nutritional conditions and antimicrobial stresses presented by the changing niches. Environmental changes are communicated by complex sensing and signaling pathways, with the transcriptional response ultimately mediated by regulatory proteins binding to motifs within the genome sequence. Unraveling the nature and hierarchy of the protein-DNA interactions involved in specific regulatory responses provides an important foundation for understanding pathogen biology.

Developments in sequencing technology over the past decade have produced a rapidly expanding body of data from which regulatory networks can be deduced, with computational prediction of transcription factor binding sites (TFBS) playing a central role in this process. Predominant data types

Corresponding author: M. Lindeberg; E-mail: ML16@cornell.edu

* The $\boldsymbol{e}$-Xtra logo stands for "electronic extra" and indicates that supplementary information is published online.

(C) 2013 The American Phytopathological Society include complete and draft genome sequences, transcriptome sequences, and sequences of the regions bound directly by various transcription factors. From these, TFBS prediction can be used to identify co-regulated genes, distinguish direct from indirect effects when evaluating expression data, and link biologically confirmed binding sites to sequence motifs identified de novo (Zambelli et al. 2012). Recent genome-wide mapping of binding sites for seven sigma factors in Sinorhizobium meliloti highlights the power of large-scale sequencing combined with TFBS prediction in advancing understanding of organismal biology (Schluter et al. 2013).

Given the investment involved in experimental confirmation of transcriptional control, optimized strategies for computational TFBS prediction represent an increasingly important tool for generating informed hypotheses (Baumbach 2010; van Hijum et al. 2009). Statistical approaches for TFBS prediction typically involve creation of hidden Markov models (HMM) or position weight matrices (PWM) from sequences of previously characterized binding sites (hereafter called training sets), thereby integrating observed variation in the binding site into the predictive model. Candidate motifs are ranked by the extent of conservation with the initial model, though establishing a cutoff that best distinguishes biologically meaningful sites from background noise can be difficult due to assumptions in the algorithm used and composition of the target genome.

Several classes of TFBS linked to pathogenicity and survival have been characterized and used for genome-wide screening in plant-pathogenic bacteria. Among those reviewed here, along with a discussion of their roles in pathogen biology, are a variety of sigma factors, including the extracytoplasmic (ECF) sigma factors, other activators linked to specific classes of virulence factors, and repressors. The extensive characterization of binding-site sequences conducted over the last decade in diverse genera and for a variety of regulators represents an invaluable resource to the plant-pathogenic research community. To leverage these accumulated data, characterized binding-site sequences have been extracted from the figures, text, and supplementary data files of the various publications in which they are described and have been assembled into training sets for use in building HMM and PWM. To aid users in applying these models to other genome sequences, the Pred_ cutoff pipeline has been developed and includes a computational step designed to empirically calibrate predictions to the composition of the target genome, providing a means for comparing results generated with different models. 
Some of the best examples of how binding-site characterization has advanced our understanding of plant pathogenicity are found in the regulatory characterization of the type III secretion system (T3SS) and its translocated effector proteins. The T3SS impacts virulence in multiple genera of gram-negative plant pathogens ranging from a critical role in plant defense suppression by Pseudomonas syringae, Xanthomonas spp., Ralstonia solanacearum, and Erwinia amylovora to more subtle impacts on bacterial multiplication and infection initiation in Dickeya dadantii (Block and Alfano 2011; Deslandes and Rivas 2012; Kay and Bonas 2009; Toth et al. 2003). T3SS are grouped into families (Cornelis 2006; McCann and Guttman 2008), with those encoded by P. syringae, E. amylovora, Pectobacterium spp., and Dickeya spp. belonging to the HrpI family and regulated by the extracytoplasmic (ECF) sigma factor HrpL. Members of the HrpII family, present in R. solanacearum and Xanthomonas spp., are regulated by a member of the AraC type family of transcriptional regulators. In both families, genome-wide predictions of the transcription factorbinding sites have made transformative contributions to our understanding of the number and nature of translocated effectors and their role in pathogenicity.

\section{HrpL: Regulation of the T3SS \\ in $P$. syringae and enteric plant pathogens.}

Genome-wide mapping of TFBS regulatory sites associated with type III secretion was pioneered with $P$. syringae pv. tomato DC3000 (DC3000) and has proven an invaluable tool in the comprehensive identification of type III effectors (T3E) throughout the species. Like other ECF sigma factors, HrpL binds to a two-block motif spanning the -10 and -35 regions (Innes et al. 1993; Xiao and Hutcheson 1994). Although strategies for HrpL binding-site identification in DC3000 have been previously reviewed (Lindeberg et al. 2006), it is worth noting that this motif continues to represent one of the most important tools for rapid prediction of effector repertoires. The HrpL HMM has been used to identify effector-gene repertoires in $P$. syringae pv. phaseolicola 1448a (Vencato et al. 2006), and various strains of $P$. syringae pv. tomato and $P$. syringae pv. maculicola (Almeida et al. 2009; Cai et al. 2011), with computational identification of HrpL binding sites in over 35 sequenced $P$. syringae strains contributing to discovery of nearly $60 \mathrm{~T} 3 \mathrm{E}$ families within the species (Baltrus et al. 2011). As additional $P$. syringae draft genome sequences are generated, $\mathrm{HrpL}$ binding-site prediction is being used to rapidly identify effector inventories, predict novel members of the HrpL regulon, and incrementally refine annotation of draft genome sequences.

As an alternative to deriving models from experimentally confirmed binding sites, candidate TFBS can be derived de novo through probabilistic sampling of regions upstream of co-regulated genes. Although the application of this approach to DC3000 genes upregulated in the presence of HrpL did not yield a motif model appreciably different from the original HrpL HMM (Fereirra et al. 2006), this strategy has been used to successfully derive motifs from expression and transcription factor-binding data for other regulators.

T3SS in the enteric plant pathogens $D$. dadantii, Pectobacterium spp., and E. amylovora are similarly regulated by $\mathrm{HrpL}$, and genome-wide motif searches for the HrpL binding site have contributed to our understanding of the distinctly different role that T3E play in these pathogens. In a study of $E$. amylovora Ea21, Boczanczy and associates (2012) used a HMM derived from training sets of confirmed $E$. amylovora and $P$. syringae HrpL binding sites to identify 28 candidate sites upstream of predicted open reading frames. McNally and associates (2011) identified 30 candidates in E. amylovora Ea1189, using an HMM derived from a different training set. Both studies led to identification of regulon members outside the main type III pathogenicity island, previously uncharacterized in E. amylovora and impacting the bacterial-host interaction. In Ea21, HopX1 and HopAK1 were confirmed for HrpLdependence and HopX1 was shown to elicit a defense response in Nicotiana tabacum. In Ea1189, EAM_2938 was shown to be a HrpL-regulated membrane protein unique to the Erwinia genus and contributing significantly to virulence on pear. Whole-genome screens for HrpL binding sites further highlight that, while the E. amylovora T3SS is required for pathogenicity, evolutionary dynamics between host and pathogen have not led to the proliferation of effectors observed in many other phytopathogen genera.

The T3SS is not required for pathogenicity in soft-rot nectrotrophs $D$. dadantii and Pectobacterium spp., though a role has been demonstrated during the early stages of infection (Toth et al. 2003). To evaluate the inventory of HrpL-dependent genes and candidate effectors in necrotrophs, Yang and associates (2010) screened the $D$. dadantii 3937 genome sequence with an HMM derived from a training set of HrpL binding sites from diverse genera; no genes with HrpL-dependent expression were found outside the main T3SS gene cluster, consistent with the evolutionary trend observed in E. amylovora. HrpL binding sites are present in the type III secretion gene cluster of $P$. carotovorum (Rantakari et al. 2001), but systematic evaluation of the complete genome, using confirmed sites as a guide, has not been reported (Bell et al. 2004).

\section{HrpX and HrpB: Regulation of the type III secretion system in Xanthomonas and Ralstonia spp.}

The hrpII family of T3SS encoded by genera Ralstonia and Xanthomonas are regulated by a complex signaling cascade unrelated to HrpL-dependent regulation, although the number of T3E, their role in pathogenicity, and the significance of motif searches in uncovering the effector repertoire have many parallels with $P$. syringae. The T3SS and substrates in $R$. solanacearum and Xanthomonas spp. are regulated by AraC-type regulators (HrpB in $R$. solanacearum and HrpX in Xanthomonas spp.), which bind to PIP or hrpII boxes, respectively. The first Xanthomonas genome sequences published were screened with a model based on experimentally confirmed PIP boxes (Fenselau and Bonas 1995; Wengelnik and Bonas 1996) and were found to encode 15 to 20 candidates per genome (da Silva et al. 2002; Thieme et al. 2005). Subsequent screening of the more than 13 Xanthomonas genome sequences now available has yielded more than 40 effector families in this genus (Bogdanove et al. 2011; Furutani et al. 2009; Jalan et al. 2011; Jiang et al. 2009; Potnis et al. 2011), confirming the utility of this approach as a means of rapid identification of regulon members (The Xanthomonas Resource database).

A similar strategy has proved effective in $R$. solanacearum. Cunnac and associates (2004) conducted a genome-wide search of $R$. solanacearum GMI1000 using confirmed sequences of the hrpII box sequence, followed by experimental confirmation of expression. A total of 48 genes with hrpII boxes had HrpB-dependent expression, 34 of which lacked homology to known virulence genes. Among those discovered using this approach were members of the GALA and AWR effector gene families, subsequently shown to play important roles in pathogenesis (Angot et al. 2006; Sole et al. 2012). The binding-site model has also been used to distinguish genes under direct HrpB control in expression analyses of $h r p B^{-}$and $h r p B$ overexpressing strains (Occhialini et al. 2005).

Exhaustive mutagenesis of conserved residues has revealed that the PIP/hrpII box motif is composed of two blocks of sequence a fixed distance apart, to which the regulator is 
believed to bind as a dimer (Cunnac et al. 2004; Koebnik et al. 2006; Tsuge et al. 2005). Given the high level of conservation, many members of the regulon can be identified using a string search for TTCG-N18-TTCG; however, analysis of natural variation, mutation of individual nucleotides, and DNA footprinting collectively support a more nuanced model of the binding site. The third and fourth base of the second block can accommodate significant variation, particularly in Xanthomonas spp., and the fifth base in each block exhibits significant conservation, contributing appreciably to the information content of the model (Koebnik et al. 2006; Tsuge et al. 2005) (Fig 1). The PIP box is located upstream of the -10 site, with the distance between being highly conserved and necessary for regulator function (Cunnac et al. 2004; Furutani et al. 2009; Koebnik et al. 2006; Mukaihara et al. 2010), though variation in the sequence of the -10 site limits its contribution to a conserved motif for genome screening.

TF

Organism

regulates

HrpL

P. syringae

T3SS/vir

HrpL

E. amylovora

T3SS/vir

HrpL

D. dadantii

T3SS/vir

HrpB

R. solanacearum

T3SS/vir

HrpX

Xanthomonas spp

T3SS/vir

RpoN

X. fastidiosa

$\mathrm{N}$ assimilation

$\mathrm{RpoH}$

X. fastidiosa

heat

Rpo

X. fastidiosa

heat/stress

RpoE

X. campestris

heat/stress

PvdS

P. syringae

Fe assimilation

VirR P. atrosepticum

CW degrading enzymes

Fur P. syringae

Fe assimilation

Rcs

E. amylovora

amylovoran

\section{PvdS and AcsS: Regulation}

of siderophore production in $\boldsymbol{P}$. syringae.

While regulators of type III secretion have been the focus of intensive motif-based discovery of genes involved in suppressing plant defense, survival in the host environment and successful pathogenicity are dependent on complex regulatory responses involving a diverse range of additional transcription factors. Among those receiving particular attention in plantpathogenic bacteria are sigma factors and transcription factors associated with two-component and quorum-sensing regulatory models. For many of these, binding-site characterization has been informed by high-throughput expression analyses, and a review of these studies highlights the complementary roles of TFBS motif identification and expression analysis in understanding the regulatory response to environmental changes.

ECF sigma factors are grouped according to their roles in the cell, with those such as HrpL involved in stress response

type

ECF $\sigma$

ECF $\sigma$

ECF $\sigma$

AraC

AraC

$\sigma 54$

$\sigma 32$

ECF $\sigma$

ECF $\sigma$

ECF $\sigma$

logo of binding motif
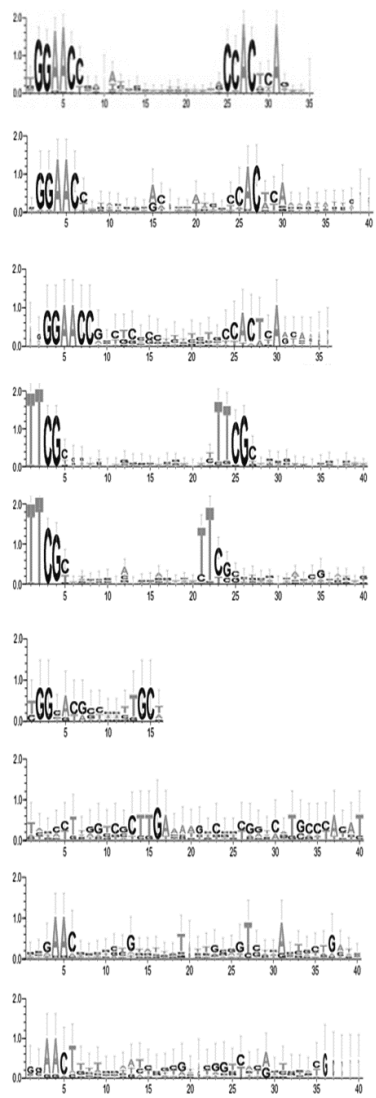

Bordes, 2011

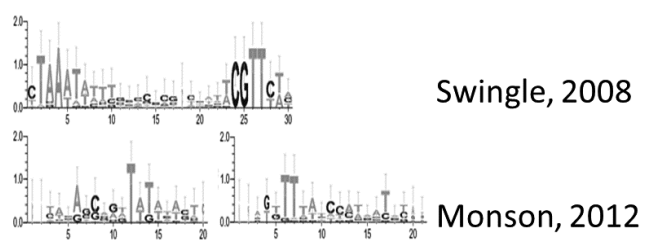

repressor (quorum-sens)

repressor

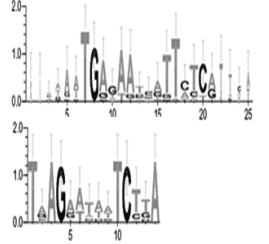

Fouts, 2002

Bocsanczy, 2012;

McNally, 2011

Yang, 2010

Cooksey \& Shi, 2009

Cunnac, 2004

Mukaihara, 2010

Koebnik, 2009, Qian, 2004

Tsuge, 2005, daSilva, 2002

daSilva, 2010

daSilva, 2007

Koide, 2006

Monson, 2012

Butcher, 2011

2-component

Fig. 1. Transcription factor (TF)-binding sites characterized in plant-pathogenic bacteria including the name of the TF, the organism in which it was characterized, its role in the cell, TF type, the logo of the binding site, and the source of sequences used in logo generation. 
while others respond primarily to iron starvation (Helmann 2002). PvdS, linked to regulation of the siderophore pyoverdine, is one of five iron starvation ECF sigma factors in $P$. syringae. To assess correspondence with the PvdS binding motif previously characterized in $P$. aeruginosa (Leoni et al. 2000; Wilson and Lamont 2000), upstream regions of PvdS regulated genes in $P$. syringae were screened for the presence of conserved sequences using Gibbs sampling and were found to contain conserved sequences in the promoter region having similarity to the $P$. aeruginosa PvdS binding site. HMM based on confirmed binding sites from the two species were compared with an HMM based on the combined set. Interestingly, the model derived from the combined set proved most effective at identification of PvdS-regulated genes in other Pseudomonas species (Swingle et al. 2008).

Binding sites for different ECF sigma factors exhibit varying degrees of similarity in their consensus motifs. While the binding sites of HrpL and PvdS are highly dissimilar, other sigma factors bind to similar sites and exhibit significant cross-regulation (Mascher et al. 2007). A recent study describes characterization of the $P$. syringae pv. syringae B728a ECF sigma factor AcsS, which regulates genes involved in synthesis and uptake of the siderophore achromobactin as well as those involved in synthesis of Psl exopolysaccharide and mangotoxin, linked to epiphytic fitness. Although a consensus-binding motif has yet to be reported, the observation that several $P$. syringae pv. syringae B728a genes in the PvdS regulon are also subject to AcsS regulation suggests that their binding sites may be similar, allowing for coordinated upregulation of siderophore production by the two Fe-responsive regulators (Greenwald et al. 2012).

\section{Sigma factor regulons in Xylella spp.}

Unlike the majority of bacterial plant pathogens which encode 7 to 14 sigma factors involved in mediation of organismal response to a range of environmental stimuli, Xylella fastidiosa has only four (Simpson and al. 2000), providing the opportunity for comprehensive experimental exploration of its regulatory response to the environment. Xylella fastidiosa encodes two heat-responsive transcriptional regulators, $\mathrm{RpoH}$, also known as alternate sigma factor 32, and the ECF sigma factor RpoE, responsive to both stress and temperature. Xylella fastidiosa genes responsive to heat were evaluated in two independent studies, with Koide and associates (2006) using a PWM developed from a training set of validated RpoH binding sites to distinguish upregulated genes under direct RpoH control. A model based on validated RpoE binding sites was likewise used to distinguish those under primary RpoE control (da Silva Neto et al. 2007). The RpoE binding site in Xylella fastidiosa was found to be more variable than that observed for the homologous sigma factor in either Escherichia coli or $P$. aeruginosa. The authors speculate that, with only one ECF sigma factor, Xylella fastidiosa can accommodate more variation in its binding site without risking biologically counterproductive induction by other regulators.

Characterization of temperature responsive genes in Xylella fastidiosa is relevant to pathogenicity, as those genes induced by increased temperature include candidate virulence genes encoding toxins and required for xylan degradation and type II secretion. It is suggested that heat-related gene induction may be important for the success of pathogens, like Xylella fastidiosa CVC, that progress more rapidly in spring and summer (Koide et al. 2006). The RpoE regulon has also been investigated in Xanthomonas spp. to explore its role in survival under stress, with binding-site prediction used to distinguish between those genes under direct and indirect RpoE-mediated control, particularly important given the very wide range of gene ex- pression impacted by a RpoE mutation including elements of the type III secretion machinery (Bordes et al. 2011). Interestingly, an RpoE binding site was found upstream of $\mathrm{RpoH}$ reinforcing the role of the $\mathrm{RpoH}$ regulon in responding to diverse types of environmental stress.

The remaining sigma factors encoded by Xylella fastidiosa are the housekeeping sigma factor RpoD and RpoN, regulating genes associated with various phenotypes, including nitrogen assimilation, particularly important to pathogens, such as $X y$ lella fastidiosa, that live in low-nutrient environments. Genes under direct RpoN regulation were identified by screening those differentially expressed in the presence and absence of nitrogen, coupled with a genome-wide screen using a PWM derived from RpoN binding sites in diverse bacteria (Barrios et al. 1999). This study provides a useful illustration of the complementary role of motif identification and expression analysis. RpoN-dependent gene expression relies on enhancer binding proteins (EBP), coexpression of which is required for induction. RpoN-dependent glnA expression, missed in the transcript analysis owing to apparent lack of expression of the required EBP under the conditions used (da Silva Neto et al. 2010), was identified in a genome-wide screen with the binding-site model.

\section{ResB: Virulence regulation in $E$. amylovora.}

The Rcs phosphorelay is a modified two-component regulatory system that controls production of the polysaccharide amylovoran in E. amylovora (Wang et al. 2012). To assess other genes and potential virulence factors under Rsc control, Wang and associates (2012) evaluated gene expression in the presence and absence of various Rcs components. In parallel, an HMM based on the sites bound by phosphorylated RcsB was developed from a set of 17 previously confirmed enterobacterial RscB binding sites. Twenty-eight genes with RcsB binding sites exhibited altered expression in response to mutagenesis of various RcsB signaling components, and the pattern of their association has provided a foundation for generating hypotheses about this complex regulatory network. Potential roles in virulence of the RcsB-regulated genes remain uncharacterized.

\section{VirR and Fur repressors: Binding-site characterization informed by ChIP-seq.}

Repressors also play an important role in modulating bacterial response to the environment. Quorum-sensing regulators such as Pectobacterium atrosepticum VirR generally act by repressing virulence gene expression until bacteria have reached a critical population threshold, while repressors of genes involved in nutrient acquisition, such as the ferric uptake regulator Fur, limit gene expression until the nutrient in question is required. Studies characterizing VirR- and Fur-binding sites highlight the contribution of ChIP-seq (Johnson et al. 2007), a widely adopted experimental approach involving binding the regulatory protein to DNA and sequencing the immunoprecipitated DNA, with de novo identification of conserved motifs performed by statistical methods (Bailey et al. 2009; Liu et al. 2001; Siddharthan et al. 2005). Unlike transcriptome analysis, direct sequencing of bound DNA can distinguish TFBS without contamination from indirect effects. Nonetheless, computational predictions with defined models remain an important tool for validation and refinement of de novo motifs as well as for screening uncharacterized sequences with models derived from ChIP-seq data. ChIP-seq was performed with VirR, a repressor of cell-wall degrading enzymes in Pectobacterium atrosepticum, to identify additional genes subject to VirR regulation. Informed by the characteristics of VirR-binding sites described in other bacteria, a VirR-binding motif was identi- 
fied from the 20 Pectobacterium atrosepticum sequence regions most highly enriched during ChIPseq, and the resulting motif was used to screen the entire genome (Monson et al. 2013). In addition to repressing siderophore production and motility, VirR was shown to activate the post-transcriptional regulator, RsmA.

Identification of genes regulated by Fur in $P$. syringae similarly involved a combination of ChIP-seq enrichment, DNA footprinting, evaluating correspondence with consensus motifs, and expression analysis (Butcher et al. 2011). Fur was shown to directly repress not only the expected Fe uptake targets but, also, nearly half the TonB dependent receptors in the cell. Like VirR, Fur appears capable of gene activation as well as repression. Mapping of Fur-binding sites has also been conducted in Xylella fastidiosa, using a model based on sequences from diverse gamma-proteobacteria, for the purpose of distinguishing the subset of Fe-responsive genes that might be directly regulated by Fur. Only $20 \%$ of Fe-responsive genes in Xylella fastidiosa were found to be associated with Fur boxes, indicating the presence of a larger network of Fe-responsive regulators (Zaini et al. 2008).

\section{A new program for optimized TFBS prediction.}

Use of statistical methods to predict the locations of TFBS in sequence data sets is a critical part of the analyses described here. Although particularly useful for identification of less conserved TFBS, even those with high conservation, such as the PIP/hrpII boxes, can benefit from statistically based search strategies, owing to significant numbers of imperfect but functional binding sites. The ability to accurately predict locations of TFBS becomes increasingly important as a source of hypotheses concerning regulation of virulence and survival mechanisms, particularly as more genome sequences are generated using next-generation technologies and having little or no experimental characterization.

TFBS predictions conducted using HMM or PWM are typically assigned a score and an expect (E) value, which are used as guides for distinguishing predictions with biological relevance. An E value of 1 theoretically corresponds to the score at which a given sequence is likely to occur by chance alone, and thereby, provides a useful metric for gauging significance. However, compositional differences among genomes can significantly impact the frequency at which a given motif occurs, such that meaningful determination of $E$ values requires sensitive calibration to the composition of the genome being evaluated. The lack of adequate calibration represents a significant shortcoming in the computational pipelines used for screening genomes with HMM or PWM. The HMMER 2.3.2 program is optimized for protein models rather than nucleic acid, and the program patser, used for screening genomes with PWM, does not include a calibration step at all.

To aid researchers in evaluating sequence data sets for the presence of binding sites previously characterized in bacterial phytopathogens, two resources have been developed. First, training sets of binding-site sequences have been assembled from the figures, text, and supplementary files of the publications discussed here and are provided in a single file (Supplementary information) and as individual .aln files at the Citrus Greening-HLB Genome Resources website. Second, a computational pipeline for binding-site prediction, Pred_cutoff, has been developed from open source software modules and specifically includes a step that empirically calibrates $E$ values to the composition of the target sequence being evaluated. As outlined in Figure 2, Pred_cutoff input data consists of the target sequence to be screened and a multiple sequence alignment of transcription factor-binding sites. If users choose to screen with an HMM, Pred_cutoff uses the programs hmmbuild and hmmsearch from the HMMER 2.3.2 suite to create a model from the input training set and screen the input genome. If a PWM-based screen is chosen, Pred_cutoff uses the makematrix and patser programs for model creation and screening (Thomas-Chollier et al. 2011).

Calibration of $\mathrm{E}$ values to the composition of the input genome is achieved through incorporation of a parallel operation that empirically determines the frequency at which a given motif will occur at random, given the genome's compositional properties. This is accomplished with the seq++ package, which uses an optimized Markov model to generate a collection of artificial or "mock" genomes with the same size and statistical properties as the input genome (Miele et al. 2005). The programs hmmsearch or patser are run on the artificial genomes, and the score at which one motif prediction occurs per artificial genome is used to empirically determine the score corresponding to an $\mathrm{E}$ value of 1 . Data output consists of a list of locations of predicted motifs with $E$ values empirically calibrated to the composition of the genome being evaluated. The predictions can be easily imported into downstream systems, such as Artemis, for curation and analysis (Carver et al. 2008). The Pred_cutoff source code is designed to be useable with limited understanding of Perl. The pipeline, together with detailed documentation in the README file can be accessed at the Citrus Greening-HLB Genome Resources website and at the open source code repository site GitHub.

In addition to providing an $E$ value that reflects actual genome composition, implementation of a generic method for $\mathrm{E}$ value computation into the pipeline provides a means for

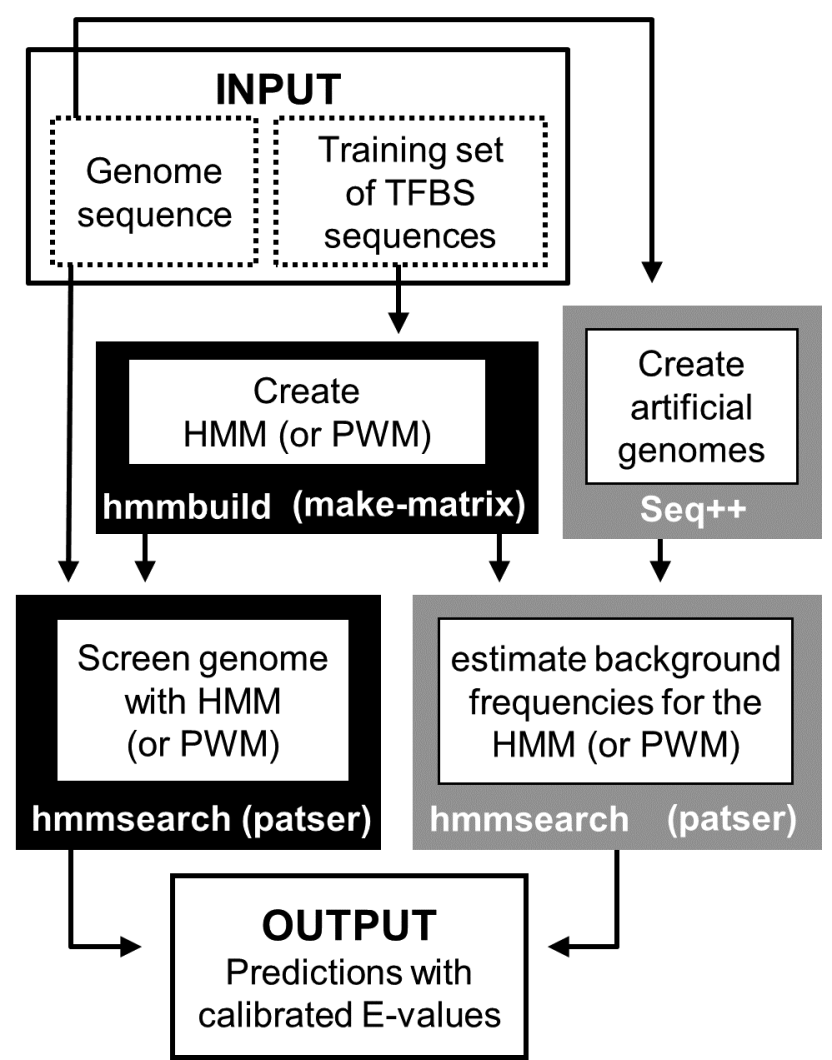

Fig. 2. Diagram of the Pred_cutoff pipeline for binding site prediction with empirically calibrated E values. The genome sequence and transcription factor binding sites (TFBS) training sets are shown in the white input box. Model creation and genome screening, using either a hidden Markov model (HMM) or position weight matrix (PWM), are indicated in the black boxes. Genome calibration consisting of generating artificial genomes and estimating background frequency for the model is shown in the gray boxes. Output consists of motif predictions with calibrated E values. 
comparing the predictive value of different training sets and of different computational approaches. In a typical application, Pred_cutoff can be used to identify training sets and computational methods that most accurately predict experimentally confirmed binding sites, yielding an optimized strategy that can be applied to related genomes, with subtle differences in genome composition accounted for in the $\mathrm{E}$ value determination.

While Pred_cutoff facilitates extrapolation of motif prediction from experimentally characterized to uncharacterized systems, users should be mindful that predictions will be more reliable when conducted between more closely related genomes in which the likelihood of motif conservation is greater and in which genome composition has not undergone dramatic shifts, such as the 20 to $30 \%$ shifts in \%GC that can occur upon genome reduction. Additionally, motifs with lower information content such as the binding sites for $\mathrm{RpoH}$ and $\mathrm{RpoE}$ will generate larger numbers of spurious predictions than those with high information content, such as binding motifs for HrpB, HrpX, and HrpL. The Pred_cutoff pipeline includes the option of limiting predictions to user-defined windows upstream of gene start sites, a feature that can help to distinguish biologically relevant sites. However, given the high error rates in start site prediction (Hyatt et al. 2010), exercising this option with poorly annotated genomes may eliminate biologically important predictions.

\section{Conclusions.}

Prediction of TFBS in sequence data sets has contributed significantly to our understanding of how plant-pathogenic bacteria respond to and survive in various environments. Central to interpretation and synthesis of genome sequence data, expression data, and ChIP-seq analyses, TFBS prediction has been used to identify co-regulated gene repertoires, uncover regulatory hierarchies, and enable comparisons of regulatory networks among strains and species. As increasing volumes of sequence data become available for experimentally uncharacterized and less tractable systems, optimized prediction methods will continue to provide a valuable foundation for hypothesis development.

\section{ACKNOWLEDGMENTS}

We thank D. J. Schneider for helpful advice on refining the Pred_cutoff pipeline. This work was supported by Citrus Research and Development Foundation grant FCATP08 \#123 and National Science Foundation grant IOS-1025642.

\section{LITERATURE CITED}

Almeida, N., Yan, S., Lindeberg, M., Studholme, D. J., Schneider, D. J. Condon, B., Liu, H., Viana, C. J., Warren, A., Evans, C., Kemen, E., MacLean, D., Angot, A., Martin, G. B., Jones, J. D., Collmer, A., Setubal, J. C., and Vinatzer, B. A. 2009. A draft genome sequence of Pseudomonas syringae pv. tomato T1 reveals a repertoire of type III related genes significantly divergent from that of $P$. syringae pv. tomato strain DC3000. Mol. Plant Microbe-Interact. 22:52-62.

Angot, A., Peeters, N., Lechner, E., Vailleau, F., Baud, C., Gentzbittel, L., Sartorel, E., Genschik, P., Boucher, C., and Genin, S. 2006. Ralstonia solanacearum requires F-box-like domain-containing type III effectors to promote disease on several host plants. Proc. Nat.l Acad. Sci. U.S.A. 103:14620-14625.

Bailey, T. L., Boden, M., Buske, F. A., Frith, M., Grant, C. E., Clementi, L., Ren, J., Li, W. W., and Noble, W. S. 2009. MEME SUITE: Tools for motif discovery and searching. Nucleic Acids Res. 37:W202-208.

Baltrus, D. A., Nishimura, M. T., Romanchuk, A., Chang, J. H., Mukhtar, M. S., Cherkis, K., Roach, J., Grant, S. R., Jones, C. D., and Dangl, J. L. 2011. Dynamic Evolution of Pathogenicity Revealed by Sequencing and Comparative Genomics of 19 Pseudomonas syringae Isolates. PLoS Pathog 7:e1002132. Published online.

Barrios, H., Valderrama, B., and Morett, E. 1999. Compilation and analysis of sigma(54)-dependent promoter sequences. Nucleic Acids Res. 27:4305-4313.

Baumbach, J. 2010. On the power and limits of evolutionary conservationunraveling bacterial gene regulatory networks. Nucleic Acids Res. 38:7877-7884.

Bell, K. S., Sebaihia, M., Pritchard, L., Holden, M. T., Hyman, L. J., Holeva, M. C., Thomson, N. R., Bentley, S. D., Churcher, L. J., Mungall, K., Atkin, R., Bason, N., Brooks, K., Chillingworth, T., Clark, K., Doggett, J., Fraser, A., Hance, Z., Hauser, H., Jagels, K., Moule, S., Norbertczak, H., Ormond, D., Price, C., Quail, M. A., Sanders, M., Walker, D., Whitehead, S., Salmond, G. P., Birch, P. R., Parkhill, J., and Toth, I. K. 2004. Genome sequence of the enterobacterial phytopathogen Erwinia carotovora subsp. atroseptica and characterization of virulence factors. Proc. Nat.l Acad. Sci. U.S.A. 101:11105-11110.

Block, A., and Alfano, J. R. 2011. Plant targets for Pseudomonas syringae type III effectors: Virulence targets or guarded decoys? Curr. Opin. Microbiol. 14:39-46.

Bocsanczy, A. M., Schneider, D. J., DeClerck, G. A., Cartinhour, S., and Beer, S. V. 2012. HopX1 in Erwinia amylovora functions as an avirulence protein in apple and is regulated by HrpL. J. Bacteriol. 194:553-560

Bogdanove, A. J., Koebnik, R., Lu, H., Furutani, A., Angiuoli, S. V., Patil, P. B., Van Sluys, M. A., Ryan, R. P., Meyer, D. F., Han, S. W., Aparna, G., Rajaram, M., Delcher, A. L., Phillippy, A. M., Puiu, D., Schatz, M. C., Shumway, M., Sommer, D. D., Trapnell, C., Benahmed, F., Dimitrov, G., Madupu, R., Radune, D., Sullivan, S., Jha, G., Ishihara, H., Lee, S. W., Pandey, A., Sharma, V., Sriariyanun, M., Szurek, B., Vera-Cruz, C. M., Dorman, K. S., Ronald, P. C., Verdier, V., Dow, J. M., Sonti, R. V., Tsuge, S., Brendel, V. P., Rabinowicz, P. D., Leach, J. E., White, F. F., and Salzberg, S. L. 2011. Two new complete genome sequences offer insight into host and tissue specificity of plant pathogenic Xanthomonas spp. J. Bacteriol. 193:5450-5464.

Bordes, P., Lavatine, L., Phok, K., Barriot, R., Boulanger, A., CastanieCornet, M. P., Dejean, G., Lauber, E., Becker, A., Arlat, M., and Gutierrez, C. 2011. Insights into the extracytoplasmic stress response of Xanthomonas campestris pv. campestris: Role and regulation of \{sigma\}E-dependent activity. J. Bacteriol. 193:246-264.

Butcher, B. G., Bronstein, P. A., Myers, C. R., Stodghill, P. V., Bolton, J. J., Markel, E. J., Filiatrault, M. J., Swingle, B., Gaballa, A., Helmann, J. D., Schneider, D. J., and Cartinhour, S. W. 2011. Characterization of the Fur regulon in Pseudomonas syringae pv. tomato DC3000. J. Bacteriol. 193:4598-4611.

Cai, R., Lewis, J., Yan, S., Liu, H., Clarke, C. R., Campanile, F., Almeida, N. F., Studholme, D. J., Lindeberg, M., Schneider, D., Zaccardelli, M., Setubal, J. C., Morales-Lizcano, N. P., Bernal, A., Coaker, G., Baker, C., Bender, C. L., Leman, S., and Vinatzer, B. A. 2011. The plant pathogen Pseudomonas syringae pv. tomato is genetically monomorphic and under strong selection to evade tomato immunity. PLoS Pathog. 7:e1002130. Published online.

Carver, T., Berriman, M., Tivey, A., Patel, C., Bohme, U., Barrell, B. G., Parkhill, J., and Rajandream, M.-A. L. 2008. Artemis and ACT: Viewing, annotating and comparing sequences stored in a relational database. Bioinformatics 24:2672-2676.

Cornelis, G. R. 2006. The type III secretion injectisome. Nat. Rev. Micro. 4:811-825.

Cunnac, S., Boucher, C., and Genin, S. 2004. Characterization of the cisacting regulatory element controlling HrpB-mediated activation of the type III secretion system and effector genes in Ralstonia solanacearum. J. Bacteriol. 186:2309-2318.

da Silva, A. C. R., Ferro, J. A., Reinach, F. C., Farah, C. S., Furlan, L. R., Quaggio, R. B., Monteiro-Vitorello, C. B., Sluys, M. A. V., Almeida, N. F., Alves, L. M. C., do Amaral, A. M., Bertolini, M. C., Camargo, L. E. A., Camarotte, G., Cannavan, F., Cardozo, J., Chambergo, F., Ciapina, L. P., Cicarelli, R. M. B., Coutinho, L. L., Cursino-Santos, J. R., ElDorry, H., Faria, J. B., Ferreira, A. J. S., Ferreira, R. C. C., Ferro, M. I. T., Formighieri, E. F., Franco, M. C., Greggio, C. C., Gruber, A., Katsuyama, A. M., Kishi, L. T., Leite, R. P., Lemos, E. G. M., Lemos, M. V. F., Locali, E. C., Machado, M. A., Madeira, A. M. B. N., Martinez-Rossi, N. M., Martins, E. C., Meidanis, J., Menck, C. F. M., Miyaki, C. Y., Moon, D. H., Moreira, L. M., Novo, M. T. M., Okura, V. K., Oliveira, M. C., Oliveira, V. R., Pereira, H. A., Rossi, A., Sena, J. A. D., Silva, C., de Souza, R. F., Spinola, L. A. F., Takita, M. A., Tamura, R. E., Teixeira, E. C., Tezza, R. I. D., Trindade dos Santos, M., Truffi, D., Tsai, S. M., White, F. F., Setubal, J. C., and Kitajima, J. P. 2002. Comparison of the genomes of two Xanthomonas pathogens with differing host specificities. Nature 417:459-463.

da Silva Neto, J. F., Koide, T., Gomes, S. L., and Marques, M. V. 2007. The single extracytoplasmic-function sigma factor of Xylella fastidiosa is involved in the heat shock response and presents an unusual regulatory mechanism. J. Bacteriol. 189:551-560. 
da Silva Neto, J. F., Koide, T., Gomes, S. L., and Marques, M. V. 2010. Global gene expression under nitrogen starvation in Xylella fastidiosa: Contribution of the sigma54 regulon. BMC Microbiol. 10:231.

Deslandes, L., and Rivas, S. 2012. Catch me if you can: Bacterial effectors and plant targets. Trends Plant Sci. 17:644-655.

Fenselau, S., and Bonas, U. 1995. Sequence and expression analysis of the hrpB pathogenicity locus of Xanthomonas campestris pv. vesicatoria which encodes eight proteins with similarity to components of the Hrp, Ysc, Spa, and Fli secretion systems. Mol. Plant-Microbe Interact. 8:845-854.

Fereirra, A. O., Myers, C. R., Gordon, J. S., Martin, G. B., Vencato, M., Collmer, A., Wehling, M. D., Alfano, J. R., Moreno-Hagelsieb, G., Lamboy, W. F., DeClerck, G. A., Schneider, D. J., and Cartinhour, S. 2006. Whole-genome expression profiling defines the HrpL regulon of Pseudomonas syringae pv tomato DC3000 allows de novo reconstruction of the Hrp cis element, and identifies novel co-regulated genes. Mol. Plant Microbe-Interact. 19:1167-1179.

Furutani, A., Takaoka, M., Sanada, H., Noguchi, Y., Oku, T., Tsuno, K., Ochiai, H., and Tsuge, S. 2009. Identification of novel type III secretion effectors in Xanthomonas oryzae pv. oryzae. Mol. Plant MicrobeInteract. 22:96-106.

Greenwald, J. W., Greenwald, C. J., Philmus, B. J., Begley, T. P., and Gross, D. C. 2012. RNA-seq analysis reveals that an ECF sigma factor, AcsS, regulates achromobactin biosynthesis in Pseudomonas syringae pv. syringae B728a. PLoS One 7:e34804. Published online.

Helmann, J. D. 2002. The extracytoplasmic function (ECF) sigma factors. Adv Microb Physiol 46:47-110.

Hyatt, D., Chen, G. L., Locascio, P. F., Land, M. L., Larimer, F. W., and Hauser, L. J. 2010. Prodigal: Prokaryotic gene recognition and translation initiation site identification. BMC Bioinformatics 11:119.

Innes, R. W., Bent, A. F., Kunkel, B. N., Bisgrove, S. R., and Staskawicz, B. J. 1993. Molecular analysis of avirulence gene avrRpt2 and identification of a putative regulatory sequence common to all known Pseudomonas syringae avirulence genes. J. Bacteriol. 175:4859-4869.

Jalan, N., Aritua, V., Kumar, D., Yu, F., Jones, J. B., Graham, J. H., Setubal, J. C., and Wang, N. 2011. Comparative genomic analysis of Xanthomonas axonopodis pv. citrumelo $\mathrm{F} 1$, which causes citrus bacterial spot disease, and related strains provides insights into virulence and host specificity. J. Bacteriol. 193:6342-6357.

Jiang, W., Jiang, B.-L., Xu, R.-Q., Huang, J.-D., Wei, H.-Y., Jiang, G.-F. Cen, W.-J., Liu, J., Ge, Y.-Y., Li, G.-H., Su, L.-L., Hang, X.-H., Tang, D.-J., Lu, G.-T., Feng, J.-X., He, Y.-Q., and Tang, J.-L. 2009. Identification of six type III effector genes with the PIP box in Xanthomonas campestris pv. campestris and five of them contribute individually to full pathogenicity. Mol. Plant Microbe-Interact. 22:1401-1411.

Johnson, D. S., Mortazavi, A., Myers, R. M., and Wold, B. 2007. Genomewide mapping of in vivo protein-DNA interactions. Science 316:14971502 .

Kay, S., and Bonas, U. 2009. How Xanthomonas type III effectors manipulate the host plant. Curr. Opin. Microbiol. 12:37-43.

Koebnik, R., Kruger, A., Thieme, F., Urban, A., and Bonas, U. 2006. Specific binding of the Xanthomonas campestris pv. vesicatoria AraCtype transcriptional activator $\operatorname{HrpX}$ to plant-inducible promoter boxes. J. Bacteriol. 188:7652-7660.

Koide, T., Vencio, R. Z., and Gomes, S. L. 2006. Global gene expression analysis of the heat shock response in the phytopathogen Xylella fastidiosa. J. Bacteriol. 188:5821-5830.

Leoni, L., Orsi, N., de Lorenzo, V., and Visca, P. 2000. Functional analysis of PvdS, an iron starvation sigma factor of Pseudomonas aeruginosa. J. Bacteriol. 182:1481-1491.

Lindeberg, M., Cartinhour, S., Myers, C. R., Schechter, L. M., Schneider, D. J., and Collmer, A. 2006. Closing the circle on the discovery of genes encoding Hrp regulon members and type III secretion system effectors in the genomes of three model Pseudomonas syringae strains. Mol. Plant Microbe-Interact. 19:1151-1158.

Liu, X., Brutlag, D. L., and Liu, J. S. 2001. BioProspector: Discovering conserved DNA motifs in upstream regulatory regions of co-expressed genes. Pac. Symp. Biocomput. 6:127-138.

Mascher, T., Hachmann, A. B., and Helmann, J. D. 2007. Regulatory overlap and functional redundancy among Bacillus subtilis extracytoplasmic function sigma factors. J. Bacteriol. 189:6919-6927.

McCann, H. C., and Guttman, D. S. 2008. Evolution of the type III secretion system and its effectors in plant-microbe interactions. New Phytol. 177:33-47.

McNally, R. R., Toth, I. K., Cock, P. J., Pritchard, L., Hedley, P. E., Morris, J. A., Zhao, Y., and Sundin, G. W. 2011. Genetic characterization of the HrpL regulon of the fire blight pathogen Erwinia amylovora reveals novel virulence factors. Mol. Plant Pathol. 13:160-173.

Miele, V., Bourguignon, P. Y., Robelin, D., Nuel, G., and Richard, H. 2005. seq++: Analyzing biological sequences with a range of Markov-related models. Bioinformatics 21:2783-2784.

Monson, R., Burr, T., Carlton, T., Liu, H., Hedley, P., Toth, I., and Salmond, G. P. 2013. Identification of genes in the VirR regulon of Pectobacterium atrosepticum and characterization of their roles in quorum sensing-dependent virulence. Environ. Microbiol. 15:687-701.

Mukaihara, T., Tamura, N., and Iwabuchi, M. 2010. Genome-wide identification of a large repertoire of Ralstonia solanacearum type III effector proteins by a new functional screen. Mol. Plant-Microbe Interact. 23:251-262.

Occhialini, A., Cunnac, S., Reymond, N., Genin, S., and Boucher, C. 2005. Genome-wide analysis of gene expression in Ralstonia solanacearum reveals that the $\operatorname{hrpB}$ gene acts as a regulatory switch controlling multiple virulence pathways. Mol. Plant-Microbe Interact. 18:938-949.

Potnis, N., Krasileva, K., Chow, V., Almeida, N. F., Patil, P. B., Ryan, R. P., Sharlach, M., Behlau, F., Dow, J. M., Momol, M., White, F. F., Preston, J. F., Vinatzer, B. A., Koebnik, R., Setubal, J. C., Norman, D. J., Staskawicz, B. J., and Jones, J. B. 2011. Comparative genomics reveals diversity among xanthomonads infecting tomato and pepper. BMC Genomics 12:146.

Rantakari, A., Virtaharju, O., Vahämiko, S., Taira, S., Palva, E. T., Saarilahti, H. T., and Romantschuk, M. 2001. Type III secretion contributes to the pathogenesis of the soft-rot pathogen Erwinia carotovora: Partial characterization of the hrp gene cluster. Mol. Plant Microbe-Interact. 14:962-968.

Schluter, J. P., Reinkensmeier, J., Barnett, M. J., Lang, C., Krol, E., Giegerich, R., Long, S. R., and Becker, A. 2013. Global mapping of transcription start sites and promoter motifs in the symbiotic alphaproteobacterium Sinorhizobium meliloti 1021. BMC Genomics 14:156.

Siddharthan, R., Siggia, E. D., and van Nimwegen, E. 2005. PhyloGibbs: A Gibbs sampling motif finder that incorporates phylogeny. PLoS Comput Biol 1:e67. Published online.

Simpson, A. J. G., Reinach, F. C., Arruda, P., Abreu, F. A., Acencio, M., Alvarenga, R., Alves, L. M., Araya, J. E., Baia, G. S., Baptista, C. S., Barros, M. H., Bonaccorsi, E. D., Bordin, S., Bove, J. M., Briones, M. R., Bueno, M. R., Camargo, A. A., Camargo, L. E., Carraro, D. M., Carrer, H., Colauto, N. B., Colombo, C., Costa, F. F., Costa, M. C., Costa-Neto, C. M., Coutinho, L. L., Cristofani, M., Dias-Neto, E., Docena, C., El-Dorry, H., Facincani, A. P., Ferreira, A. J., Ferreira, V. C., Ferro, J. A., Fraga, J. S., Franca, S. C., Franco, M. C., Frohme, M. Furlan, L. R., Garnier, M., Goldman, G. H., Goldman, M. H., Gomes, S. L., Gruber, A., Ho, P. L., Hoheisel, J. D., Junqueira, M. L., Kemper, E. L., Kitajima, J. P., Krieger, J. E., Kuramae, E. E., Laigret, F., Lambais, M. R., Leite, L. C., Lemos, E. G., Lemos, M. V., Lopes, S. A., Lopes, C. R., Machado, J. A., Machado, M. A., Madeira, A. M. Madeira, H. M., Marino, C. L., Marques, M. V., Martins, E. A., Martins, E. M., Matsukuma, A. Y., Menck, C. F., Miracca, E. C., Miyaki, C. Y., Monteriro-Vitorello, C. B., Moon, D. H., Nagai, M. A., Nascimento, A. L., Netto, L. E., Nhani, A., Jr., Nobrega, F. G., Nunes, L. R., Oliveira, M. A., de Oliveira, M. C., de Oliveira, R. C., Palmieri, D. A., Paris, A., Peixoto, B. R., Pereira, G. A., Pereira, H. A., Jr., Pesquero, J. B., Quaggio, R. B., Roberto, P.G., Rodrigues, V., de, M. R. A. J., de Rosa, V. E., Jr., de Sa, R. G., Santelli, R. V., Sawasaki, H. E., da Silva, A. C., da Silva, A. M., da Silva, F. R., da Silva, W. A., Jr., da Silveira, J. F., Silvestri, M. L., Siqueira, W. J., de Souza, A. A., de Souza, A. P., Terenzi, M. F., Truffi, D., Tsai, S. M., Tsuhako, M. H., Vallada, H., Van Sluys, M. A., Verjovski-Almeida, S., Vettore, A. L., Zago, M. A., Zatz, M., Meidanis, J., and Setubal, J. C. 2000. The genome sequence of the plant pathogen Xylella fastidiosa. Nature 406:151-157.

Solé, M., Popa, C., Mith, O., Sohn, K. H., Jones, J. D. G., Deslandes, L. and Valls, M. 2012. The awr gene family encodes a novel class of Ralstonia solanacearum type III effectors displaying virulence and avirulence activities. Mol. Plant Microbe-Interact. 25:941-953.

Swingle, B., Thete, D., Moll, M., Myers, C. R., Schneider, D. J., and Cartinhour, S. 2008. Characterization of the PvdS-regulated promoter motif in Pseudomonas syringae pv. tomato DC3000 reveals regulon members and insights regarding PvdS function in other pseudomonads. Mol. Microbiol. 68:871-889.

Thieme, F., Koebnik, R., Bekel, T., Berger, C., Boch, J., Buttner, D., Caldana, C., Gaigalat, L., Goesmann, A., Kay, S., Kirchner, O., Lanz, C., Linke, B., McHardy, A.C., Meyer, F., Mittenhuber, G., Nies, D.H., Niesbach-Klosgen, U., Patschkowski, T., Ruckert, C., Rupp, O., Schneiker, S., Schuster, S.C., Vorholter, F.-J., Weber, E., Puhler, A., Bonas, U., Bartels, D., and Kaiser, O. 2005. Insights into genome plasticity and pathogenicity of the plant pathogenic bacterium Xanthomonas campestris pv. vesicatoria revealed by the complete genome sequence. J. Bacteriol. 187:7254-7266.

Thomas-Chollier, M., Defrance, M., Medina-Rivera, A., Sand, O., Herrmann, C., Thieffry, D., and van Helden, J. 2011. RSAT 2011: Regulatory sequence analysis tools. Nucleic Acids Res. 39:W86-91. 
Toth, I. K., Bell, K. S., Holeva, M. C., and Birch, P. R. J. 2003. Soft rot erwiniae: From genes to genomes. Mol. Plant Pathol. 4:17-30.

Tsuge, S., Terashima, S., Furutani, A., Ochiai, H., Oku, T., Tsuno, K., Kaku, H., and Kubo, Y. 2005. Effects on promoter activity of base substitutions in the cis-acting regulatory element of HrpXo regulons in Xanthomonas oryzae pv. oryzae. J. Bacteriol. 187:2308-2314.

van Hijum, S. A., Medema, M. H., and Kuipers, O. P. 2009. Mechanisms and evolution of control logic in prokaryotic transcriptional regulation. Microbiol. Mol. Biol. Rev. 73:481-509.

Vencato, M., Tian, F., Alfano, J. R., Buell, C. R., Cartinhour, S., DeClerck, G. A., Guttman, D. S., Stavrinides, J., Joardar, V., Lindeberg, M. Bronstein, P. A., Mansfield, J. W., Myers, C. R., Collmer, A., and Schneider, D. J. 2006. Bioinformatics-enabled identification of the HrpL regulon and type III secretion system effector proteins of Pseudomonas syringae pv. phaseolicola 1448A. Mol. Plant MicrobeInteract. 19:1193-1206

Wang, D., Qi, M., Calla, B., Korban, S. S., Clough, S., Cock, P., Sundin, G. W., Toth, I., and Zhao, Y. F. 2012. Genome-wide identification of genes regulated by the Rcs phosphorelay system in Erwinia amylovora. Mol Plant Microbe Interact. 25:6-17.

Wengelnik, K., and Bonas, U. 1996. HrpXv, an AraC-type regulator, activates expression of five of the six loci in the hrp cluster of Xanthomonas campestris pv. vesicatoria. J. Bacteriol. 178:3462-3469.

Wilson, M. J., and Lamont, I. L. 2000. Characterization of an ECF sigma factor protein from Pseudomonas aeruginosa. Biochem. Biophys. Res. Commun. 273:578-583.
Xiao, Y., and Hutcheson, S. 1994. A single promoter sequence recognized by a newly identified alternate sigma factor directs expression of pathogenicity and host range determinants in Pseudomonas syringae. J. Bacteriol. 176:3089-3091.

Yang, S., Peng, Q., Zhang, Q., Zou, L., Li, Y., Robert, C., Pritchard, L., Liu, H., Hovey, R., Wang, Q., Birch, P., Toth, I. K., and Yang, C. H. 2010. Genome-wide identification of HrpL-regulated genes in the necrotrophic phytopathogen Dickeya dadantii 3937. PLoS One 5:e13472. Published online.

Zaini, P. A., Fogaca, A. C., Lupo, F. G., Nakaya, H. I., Vencio, R. Z., and da Silva, A. M. 2008. The iron stimulon of Xylella fastidiosa includes genes for type IV pilus and colicin V-like bacteriocins. J. Bacteriol. 190:2368-2378.

Zambelli, F., Pesole, G., and Pavesi, G. 2012. Motif discovery and transcription factor binding sites before and after the next-generation sequencing era. Brief. Bioinform. 14:225-237.

\section{AUTHOR-RECOMMENDED INTERNET RESOURCES}

Citrus Greening-HLB Genome Resources website: citrusgreening.org/Pred_cutoff.html

GitHub Open Source Code Repository: github.com/suryasaha/Pred_cutoff

The Xanthomonas Resource database: xanthomonas.org

Pseudomonas syringae Genome Resources website: pseudomonas-syringae.org 